\title{
Employee engagement within the NHS: a cross-sectional study
}

\author{
Yadava Bapurao Jeve*, Christina Oppenheimer, Justin Konje
}

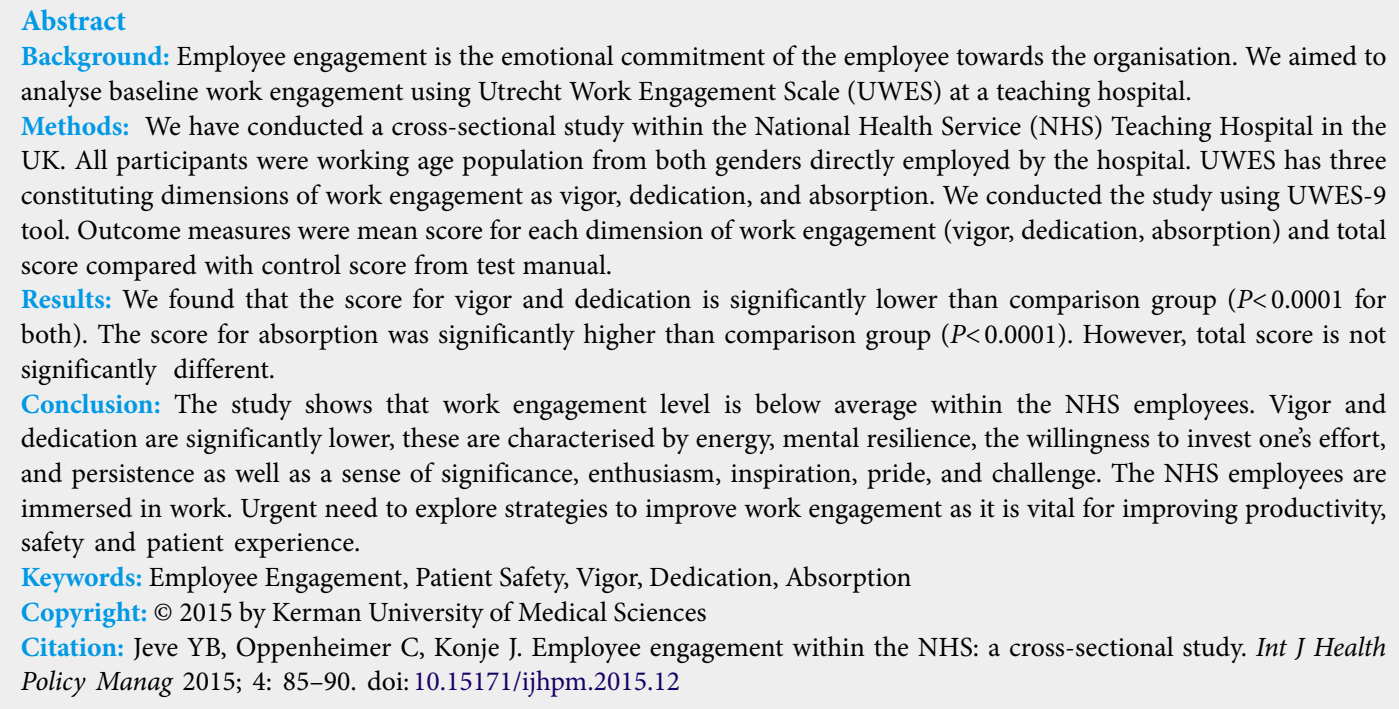

Background: Employee engagement is the emotional commitment of the employee towards the organisation. We aimed to analyse baseline work engagement using Utrecht Work Engagement Scale (UWES) at a teaching hospital.

Methods: We have conducted a cross-sectional study within the National Health Service (NHS) Teaching Hospital in the UK. All participants were working age population from both genders directly employed by the hospital. UWES has three constituting dimensions of work engagement as vigor, dedication, and absorption. We conducted the study using UWES-9 tool. Outcome measures were mean score for each dimension of work engagement (vigor, dedication, absorption) and total score compared with control score from test manual.

Results: We found that the score for vigor and dedication is significantly lower than comparison group $(P<0.0001$ for both). The score for absorption was significantly higher than comparison group $(P<0.0001)$. However, total score is not significantly different.

Conclusion: The study shows that work engagement level is below average within the NHS employees. Vigor and dedication are significantly lower, these are characterised by energy, mental resilience, the willingness to invest one's effort, and persistence as well as a sense of significance, enthusiasm, inspiration, pride, and challenge. The NHS employees are immersed in work. Urgent need to explore strategies to improve work engagement as it is vital for improving productivity, safety and patient experience.

Keywords: Employee Engagement, Patient Safety, Vigor, Dedication, Absorption

Copyright: (C) 2015 by Kerman University of Medical Sciences

Citation: Jeve YB, Oppenheimer C, Konje J. Employee engagement within the NHS: a cross-sectional study. Int J Health Policy Manag 2015; 4: 85-90. doi: 10.15171/ijhpm.2015.12

\section{Article History:}

Received: 20 September 2014 Accepted: 3 January 2015 ePublished: 4 January 2015

\section{Key Messages}

Implications for policy makers

- This research highlights the need of addressing employee engagement within publically funded organisations.

- Policy-makers should evaluate level of work engagement within their respective organisation.

- They should design and plan strategies to improve work engagement. This will help to improve patient safety and quality of care.

Implications for public

Employee engagement is a concept of emotional commitment the employee has to the organisation and its goals. It evaluates that whether an employee will dedicate his maximum potential to the organisation, whether employee will go beyond job descriptions and his role for benefit of organisation. Work engagement is directly related to patient safety, quality of care, patient satisfaction, employee rotations rate and overall financial benefit of the organisation. Our research highlights urgent need to formulate strategies to improve employee engagement in publically funded health sector. Greater engagement will lead to better care for the public.

\section{Background}

Employee engagement is defined as the emotional commitment the employee has to the organisation and its goals. An engaged employee is therefore fully involved in, enthusiastic about their work and willing to give discretionary effort towards the success of the organisation. Research into work engagement originated from work on job burnout (1). Burnout is defined as a state of exhaustion in which an individual is cynical about occupational values and doubtful about his or her performance abilities (2).

The study of work engagement coincided with the emergence of positive psychology (3). Work engagement is a positive, fulfilling work-related state of mind that is characterized by vigor, dedication, and absorption $(4,5)$.

It is important to study work engagement because the research has consistently shown that employee engagement is powerfully linked to a range of business success factors such as: employee performance and efficiency $(6,7)$, productivity $(8)$, safety $(9,10)$, attendance and retention $(6,11)$, customer service and satisfaction (12), customer loyalty, and profitability (13). Many researchers have found positive relationships between general workplace attitudes and service intentions, customer perceptions (14) and individual performance outcomes (15). The quality of an organisation's human resources is thought to be a leading indicator of its growth and sustainability.

There is very little evidence available on employee engagement 
and interventions in the public health sector. The limited evidence suggests that engaged staff provide safer patient care (16). High level of employee engagement is related to patientcentred care, patient safety culture and the quality of care provided (17). Prins and colleagues (18) found that Dutch resident doctors who were more engaged were significantly less likely to make mistakes. Dawson's review, funded by Kings Fund to review engagement within the National Health Service (NHS), showed that engagement has many significant associations with patient satisfaction, mortality, infection rates, Annual Health Check scores, as well as staff absenteeism and turnover (19). Staff reporting more positive experiences within an NHS trust lead to better outcomes for that trust. MacLeod and Clarke performed a review of engagement for the UK government and revealed that two companies who are performing strongly, $\mathrm{O} 2$ and Sainsbury's, believed that their recent growth was built on transforming their approach to their workforce using sophisticated engagement models (20). The Boorman Review of the NHS staff mental health found a strong link between stress and poor trust performance (21). The importance of employee engagement was highlighted after the Francis Report, the largest public enquiry in the UK. The Robert Francis report states that the failure in clinical governance at Mid Staffordshire NHS Foundation Trust was caused by 'a lack of clinical engagement, whatever, then gets turned out by the Department of Health, whatever initiatives are started at the top, unless the clinical soil is fertile, the seeds will inevitably fall to stony ground at the trust level' (22). The employer and employee are connected at the rational level, at the emotional level and at motivational level (23). This results in optimal positive output from the engaged employee (7). Research shows that nine out of every ten workers in the world want to take on challenges and are ready to put discretionary effort into their jobs (24). Unfortunately, only two employees in ten do so (25). This discrepancy called as "the engagement gap" may seem standard but it does not have to be. Positive employee engagement is vital for the NHS as it is the largest public sector organisation and employer in the UK. There are five steps described by Harrison et al. (26) to develop positive work engagement culture. The first step is to evaluate the tools and existing employee engagement followed by connecting employee to the values of organisation, to improve the engagement using communication and branding. Finally, to communicate on every platform to get into the minds of employees (26). Gallup questionnaire and the Utrecht Work Engagement Scale (UWES) are the most commonly used tools to measure employee engagement. The present study is aimed to understand the current level of employee engagement at one of the largest teaching hospital in the UK.

\section{Literature review}

In recent years, work engagement has become a well-known concept in management. Variety of research is beginning to converge around a common conceptualization of work engagement as connoting high levels of personal investment in the work tasks performed on a job $(5,9,10,27,28)$.

\section{Defining work engagement}

Employee engagement term is used at different times to refer to psychological states, traits, and behaviours as well as their antecedents and outcomes (29) In 1990, William Kahn defined the concept of work engagement as "the harnessing of organisational members' selves to their work roles" (10). It is a psychological state in which employees feel that they have a vested interest in the company's success and they are willing and motivated to perform to levels that exceed those in their job description. Work engagement is fundamentally a motivational concept that represents the active allocation of personal resources toward the tasks associated with a work role $(30,31)$. Khan's definition has significant characteristics that suggests the work engagement should refer to a psychological connection with the performance of work tasks rather than an attitude toward features of the organisation or the job (1). The other characteristics of the work engagement highlights the self-investment of personal resources in work. Therefore engagement represents a commonality among physical, emotional, and cognitive energies that individuals bring to their work role (31). But this means a measure such as the Gallup Workplace Audit (7) does not conform to this conceptualization because it refers to work conditions not the work task. However tools like UWES and the May et al. (9) scale measure refers to the harnessing of employees' selves to their work roles.

\section{Work engagement and employee engagement}

Most of the literature to date has approached engagement from either the individual or group-level, while there has been little effort to understand the employee engagement process across the organisational levels. The words 'work engagement' and 'employee engagement' are often used as synonymous. However work engagement is employee's commitment towards work at individual level and employee engagement is the process at organisational level. The studies found that group engagement is distinct from, yet positively related to personal engagement (31). It is also positively related to group performance outcomes, including proficiency, adaptivity, and proactivity (31). An increased understanding of the engagement process at work is particularly valuable given to its strong linkage to important attitudinal and behavioural outcomes (9,31). Although many researchers explain engagement as a relatively stable, individual difference variable that varies between persons $(5,11)$. Recent research has indicated that the engagement is subject to moderate daylevel fluctuations around an average level (32). Study of the employees from five German organisations suggest that both engagement when being at work and disengagement when being away from work are most beneficial for employees' affective states (32).

\section{Conceptual framework}

Macey proposed the framework based on psychological state engagement, behavioural engagement and trait engagement. $\mathrm{He}$ also proposed that the measurement of these three dimensions of engagement is possible via employee surveys (29). Macey proposes that job characteristics, leadership and personality traits should all be directly related to the work engagement and, thus, indirectly related to the performance. This frame work was drawn from studying charismatic leadership job characteristics of theory and personality (33). Christian et al. (34) proposed a modified version of the 
framework put forth by Macey. This framework was useful as it offered a clear description of engagement's nomological network and it specifies engagement as a mediating variable situated among its antecedents and outcomes. The evidence suggests that predecessor like job characteristics, leadership, and dispositional characteristics influence proximal motivational factors in order to affect job performance (35-37). Engagement focuses on work performed at a job and represents the willingness to dedicate physical, cognitive, and emotional resources to this work (34).

\section{Measurement of engagement}

There are various tools proposed in the literature. Based on the concept of engagement and its psychometric properties these tools are developed. Utrecht UWES-9 is widely used instrument with proven validity (38). When it was compared with May, Gilson and Harter scale which measures cognitive, emotional and physical factors, UWES performed better (39). Gallup Q12 is commercially available tool to measure work engagement (40). Work Experience Measurement Scale (WEMS), has a potential of being a useful tool in workplace health promotion to enhance positive human capabilities and resources to improve work performance (41). A new instrument called the Scale of Work Engagement and Burnout (SWEBO) measuring the state mood of burnout and work engagement was developed during 2007. SWEBO presents a psychometrically sound alternative for measuring burnout and work engagement (42). The Intellectual, Social, Affective Engagement Scale (ISA Engagement Scale) is built on Kahn's theory and three key dimensions such as a workrole focus, activation and positive affect (43). The critiques of such surveys warn engagement surveys alone will not give sufficient information to enable managers to manage engagement effectively (44).

\section{Methods}

This study was conducted using the UWES-9 test (11) to measure and analyse employee engagement. The UWES is prepared by analysing the three dimensions of work engagement namely vigor, dedication, and absorption. These three dimensions are examined by 9 questions. This tool is internationally validated and accepted to measure work engagement. UWES-9 scores have acceptable psychometric properties and can be used in studies on positive organisational behaviour (11). We used all NHS employees working within the Women's and Children's clinical division of University Teaching Hospital United Kingdom as a study population. The nine questions of UWES-9 survey are shown in Tables 1 and 2.

In order to avoid bias from specific connotations related to 'work engagement' this term was not used in the title of the questionnaire. We chose the more neutral term 'Work and Well-being Survey'. We send the introductory information stating that this survey is aimed to study work and wellbeing within our organisation, participation is voluntary and responses will be analysed anonymously. Work engagement is not only an individual phenomenon, but also occurs in groups; that is, it seems that employees in some teams or parts of an organisation are more engaged than others (45). For this reason we have used one group within an organisation as the study population. All participants were directly employee of the organisation. The survey was sent to everyone to avoid any selection bias. The survey was sent to the study population using a web-based survey. The participants were from all working groups including doctors, nurses, and administration staff. All participants represented both genders, were in the working age population, and were directly employed by the NHS Hospital. There was no direct working relation between surveyor and participants to avoid bias and no managers were involved to send or analyse the survey. All responses were analysed anonymously. Work engagement was measured and analysed as described by UWES-9 test manual (11). Responses to items were graded on a frequency scale varying from 0 (never) to 6 (always) as described in the original test. We compared the results with the UWES-9 international database which is derived from various sectors and countries as a control.

Table 1. Work and well-being survey UWES-9 questions

\begin{tabular}{|c|c|c|c|}
\hline Number & Questions & Dimension Represented & Psychometric Characteristics \\
\hline 1 & At my work, I feel bursting with energy & \multirow{3}{*}{ Vigor } & \multirow{3}{*}{$\begin{array}{l}\text { Energy, mental resilience, the willingness to invest one's } \\
\text { effort, and persistence }\end{array}$} \\
\hline 2 & When I get up in the morning, I feel like going to work & & \\
\hline 3 & At my job, I feel strong and vigorous & & \\
\hline 4 & I am enthusiastic about my job & \multirow{3}{*}{ Dedication } & \multirow{3}{*}{$\begin{array}{l}\text { A sense of significance, enthusiasm, inspiration, pride, } \\
\text { and challenge }\end{array}$} \\
\hline 5 & My job inspires me & & \\
\hline 6 & I am proud of the work that I do & & \\
\hline 7 & I feel happy when I am working intensely & \multirow{3}{*}{ Absorption } & \multirow{3}{*}{$\begin{array}{l}\text { Being engrossed in one's work, to the extent to which } \\
\text { time passes quickly and it is difficult to detach oneself } \\
\text { from work }\end{array}$} \\
\hline 8 & I am immersed in my work & & \\
\hline 9 & I get carried away when I am working & & \\
\hline
\end{tabular}

Table 2. Scale to response above statements

\begin{tabular}{ccccccc}
\hline Never & Almost never & Rarely & Sometimes & Often & Very often & Always \\
\hline 0 score & 1 score & 2 score & 3 score & 4 score & 5 score & 6 score \\
& A few times a year or less & Once a month or less & A few times a month & Once a week & A few times a week & Everyday \\
\hline
\end{tabular}




\section{Results}

Off the 299 participants who received the survey questions $241(80.60 \%)$ completed it. We did not analyse the responses based on different working groups such as nurses, doctors or administrative staff to avoid group specific bias and to ensure higher degree of confidentiality. All data was analysed collectively and was compared with standard test manual. The average time taken to complete it was 153 seconds. The results were analysed as per test manual. We used PRISM 6 statistical software and Microsoft Excel (46). The results are shown in Table 3.

The mean score for vigor was significantly lower than control group $(P<0.0001,95 \% \mathrm{CI}:-0.51$ to -0.19$)$. The score for dedication was also significantly lower than that of control group. $(P<0.0001, \mathrm{CI}:-0.55$ to -0.21$)$. However the score for absorption was significantly higher $(P<0.0001, \mathrm{CI}: 0.53$ to 0.89 ). The total score in both groups was comparable $(P=0.8973$, CI: 0.16 to 0.14$)$. The total score shows the average level of work engagement within the study group.

\section{Discussion}

To the best of our knowledge this is the first of such a study within NHS employees. Our results suggest that the scores for two dimensions, vigor and dedication, is significantly lower when compared with the international database. However, the third dimension, absorption, is significantly higher than the comparison group. The overall engagement score is not significantly different in both groups. These findings are significant as they reflect the working culture within the NHS. Vigor is characterized by energy, mental resilience, the willingness to invest one's effort, and persistence. Dedication is characterized by a sense of significance, enthusiasm, inspiration, pride, and challenge. Absorption is characterized by being engrossed in one's work, to the extent to which time passes quickly and it is difficult to detach oneself from work (11). Our study suggested that the employees are engrossed in their work but they lack energy, enthusiasm, pride and challenge. The overall work engagement score is not significantly different because the score for absorption is significantly higher. High score for absorption suggests that the employees are engrossed in their work and they cannot detach themselves from work. However significantly lower score for vigior and dedication represents lack of a sense of significance, enthusiasm, inspiration and pride as well as lower energy, lower mental resilience, lack of willingness to invest their efforts, and absence of persistence. The total score is classed as an average based on UWES-9 test. The results show that there is a need to improve upon vigor and dedication. Many of the decisions and actions the employees carry out are influenced by their own internal motivation

Table 3. Results

\begin{tabular}{lccc}
\hline Dimension & $\begin{array}{c}\text { Mean score (SD) } \\
\text { study group }\end{array}$ & $\begin{array}{c}\text { Mean score (SD) } \\
\text { control Group }\end{array}$ & P-value \\
\hline Population (N) & 241 & 12631 & - \\
Vigor & $3.83(1.25)$ & $4.18(1.24)$ & $P<0.0001$ \\
Dedication & $3.90(1.28)$ & $4.28(1.36)$ & $P<0.0001$ \\
Absorption & $4.39(1.26)$ & $3.68(1.43)$ & $P<0.0001$ \\
Total score & $4.04(1.29)$ & $4.05(1.19)$ & $P=0.8973$ \\
\hline
\end{tabular}

and drive. Work engagement is a key diver of quality of care. Engaged individuals are energetic and feel connected to their work. The engaged staff members are better equipped to deal with job demands (11). Study conducted at an Irish hospital support the importance of health service organisations deploying organisational resources to foster employee work engagement (47). Workaholism and work engagement are two different concepts that are oppositely related to well-being and performance. Various studies clearly shows the differences between two important work experiences work engagement and workaholism (28). The concept of workaholism may result in various problems such as burnout syndrome, work and family conflict, and overload stress phenomena for the individuals. It results in reduction in the productivity and increase in the labour turnover for the organisations (48). Research show that workaholism was related to an increase in ill-health and to a decrease in life satisfaction $(48,49)$. In contrast, work engagement was related to a decrease in ill health and to increases in both life satisfaction and job performance (49). It is vital to implement deliberate strategies to improve the work engagement. The evidence indicates that the work engagement can be improved through adopting certain workplace behavioural health practices that address supervisory communication, job design, resource support, working conditions, corporate culture, and leadership style (50). The right balance between all three dimensions of work is required. In an anticipation of the challenges of the next decade, healthcare organisations must achieve a higher degree of employee engagement in order to enhance organisational performance and profitability (51). There is a need to have an effective internal communication of organisational goals and strategy. There is a good evidence suggesting effective internal communication is a prerequisite for organisational success (52). Therefore employees should be treated as internal customers according to few authors (53). The evidence shows that the companies which engage their employees grow earnings at a rate that is 2.6 times faster than companies that do not (54). Positive enforcement of work engagement should be incorporated in the culture change within the NHS. Everyday tasks should be turned into employee engagement opportunities (55). Study shows that employee engagement's foundation is trust, respect, and performance, however, engagement is dynamic as it changes over the course of an employee's tenure (56). The various mechanisms to create employee engagement culture include defining the employee's role in fulfilling the organisation's purpose, selecting employees with capability and passion, supporting and valuing the employee, creating sustainable reward systems, and developing feedback and reinforcement mechanism are suggested (51). The major limitation of the present study is not using an entirely comparable occupational cohort. However, this study provides the baseline data on work engagement for the NHS. It highlights the issues that managers need to focus to improve productivity of public sector organisations like the NHS. It is hoped that this evidence will further stimulate the research on this area of positive organisational behaviour within the NHS.

\section{Conclusion}

Our study shows that work engagement level was average to 
below average within NHS employees. Vigor and dedication were significantly lower; these are characterised by energy, mental resilience, the willingness to invest one's effort, and persistence as well as a sense of significance, enthusiasm, inspiration, pride, and challenge. Our study suggests the NHS employees are immersed in work. Literature suggests that work engagement is vital for improving productivity, safety and patient experience. There is a need to undertake multicentre studies involving large sample size within public sector health services. Further research is required before drawing any conclusion. The public healthcare managers urgently need to focus upon strategies to measure, analyse and improve work engagement among the employees.

Ethical issues

Ethical approval was not required for this study as per local policy.

\section{Competing interests}

The authors declare that they have no competing interests.

\section{Authors' contributions}

YBJ led this study. He designed, conducted and analyzed the study. CO and JK contributed significantly to design the study and to write the paper.

\section{References}

1. Maslach C, Schaufeli WB, Leiter MP. Job burnout. Annu Rev Psychol 2001; 52: 397.

2. Maslach C, Schaufeli WB. Historical and conceptual development of burnout. In: Schaufeli WB, C Maslach, T Marek, editors. Professional burnout: Recent developments in theory and research. Philadelphia, PA: Taylor \& Francis; 1993. p. 1-16.

3. Llorens S, Bakker AB, Schaufeli W, Salanova M. Testing the robustness of the job demands-resources model. Int $J$ Stress Manag 2006; 13: 378-91. doi: 10.1037/1072-5245.13.3.378

4. Schaufeli W, Salanova M. Work engagement: On how to better catch a slippery concept. European Journal of Work and Organizational Psychology 2011; 20: 39-46. doi: 10.1080/1359432X.2010.515981

5. Schaufeli WB, Salanova M, González-Romá V, Bakker AB. The measurement of engagement and burnout: $A$ two sample confirmatory factor analytic approach. J Happiness Stud 2002; 3: 71-92. doi: 10.1023/A:1015630930326

6. Holbeche L. How to make work more meaningful. Personnel Today [serial on the internet]. 2004. Available from: http://www. personneltoday.com/hr/how-to-make-work-more-meaningful/

7. Harter JK, Schmidt FL, Hayes TL. Business-Unit-Level relationship between employee satisfaction, employee engagement, and business outcomes: a meta-analysis. $J$ Appl Psychol 2002; 87: 268-79.

8. Maslach C, Schaufeli WB, Leiter MP. Job burnout. Annu Rev Psychol 2001; 52: 397-422. doi: 10.1146/annurev.psych.52.1.397

9. May DR, Gilson RL, Harter LM. The psychological conditions of meaningfulness, safety and availability and the engagement of the human spirit at work. J Occup Organ Psychol 2004; 77: 11-37.

10. Kahn WA. Psychological conditions of personal engagement and disengagement at work. Acad Manage J 1990; 33: 692-724. doi: $10.2307 / 256287$

11. Schaufeli WB, Bakker AB, Salanova M. The Measurement of Work Engagement With a Short Questionnaire: A Cross-National Study. Educational and Psychological Measurement 2006; 66: 701-16. doi: $10.1177 / 0013164405282471$

12. Roberts DR, Davenport TO. Job Engagement: Why It's Important and How to Improve It. Employ Relat Today 2002; 29: 21-9.

13. Seijts GH, Crim D. What engages employees the most or, The Ten C's of employee engagement. Ivey Business Journal 2006; 70: $1-5$.

14. Schmit MJ, Allscheid SP. Employee attitudes and customer satisfaction: making theoretical and empirical connections. Pers Psychol 1995; 48: 521-36.

15. laffaldano MT, Muchinsky PM. Job satisfaction and job performance: A meta-analysis. Psychol Bull 1985; 97: 251-73. doi: 10.1037/0033-2909.97.2.251

16. Gilbert S, Laschinger HK, Leiter M. The mediating effect of burnout on the relationship between structural empowerment and organizational citizenship behaviours. J Nurs Manag 2010; 18: 339-48. doi: 10.1111/j.1365-2834.2010.01074.x

17. Lowe G. How employee engagement matters for hospital performance. Healthc Q 2012; 15: 29-39.

18. Prins JT, Gazendam-Donofrio SM, Dillingh GS, van de Wiel HB, van der Heijden FM, Hoekstra-Weebers JE. The relationship between reciprocity and burnout in Dutch medical residents. Med Educ 2008; 42: 721-8. doi: 10.1111/j.1365-2923.2008.03041.x

19. Leadership and engagement for improvement in the NHS: Report from The Kings Fund Leadership Review. 2012. Available from: http://www.kingsfund.org.uk/sites/files/kf/field/ field_publication_file/leadership-for-engagement-improvementnhs-final-review2012.pdf

20. Juniper B. Engagement versus wellbeing. Occupational Health 2012; 64: 26.

21. O'Reilly N. Boorman urges $\mathrm{NHS} \mathrm{OH}$ staff to work with HR to improve health. Occupational Health 2010; 62: 8.

22. Palmer E. Mid Staffordshire Report: Change Needed at NHS 'on Every Level' [internet]. 2013. Available from: http://www. ibtimes.co.uk/mid-staffordshire-hospital-report-nhs-failingchange-432151

23. Adyasha R. A Motivated Employee: A Qualitative Study on various Motivational Practices used in Organizations. Aweshkar Research Journal 2013; 15: 98-103.

24. Handa M, Gulati A. Employee Engagement. Journal of Management Research 2014; 14: 57-67.

25. Catlette B, Hadden R. Discretionary Effort. Sales and Service Excellence 2008; 8: 8.

26. Harrison AG. 5 steps to employee engagement: Improving your goals for organizational success. Public Relations Tactics 2012; 19: 10.

27. Dalal RS, Brummel BJ, Wee S, Thomas LL. Defining Employee Engagement for Productive Research and Practice. Ind Organ Psychol 2008; 1: 52-5. doi: 10.1111/j.1754-9434.2007.00008.x

28. Bakker AB, Shimazu A, Demerouti E, Shimada K, Kawakami N. Work engagement versus workaholism: a test of the spillovercrossover model. Journal of Managerial Psychology 2014; 29: 63-80. doi: 10.1108/JMP-05-2013-0148

29. Macey WH, Schneider B. The Meaning of Employee Engagement. Ind Organ Psychol 2008; 1: 3-30. doi:10.1111/j.17549434.2007.0002.x

30. Breland BT, Donovan JJ. The Role of State Goal Orientationin the Goal Establishment Process. Human Performance 2005; 18: 23-53. doi: 10.1207/s15327043hup1801_2

31. Luth MT, May DR. Toward a multilevel framework of engagement and performance at work. Academy of Management Proceedings 2012; 2012: 1. doi: 10.5465/AMBPP.2012.14

32. Sonnentag S, Mojza EJ, Binnewies C, Scholl A. Being engaged at work and detached at home: A week-level study on work engagement, psychological detachment, and affect. Work Stress 2008; 22: 257-76. doi: 10.1080/02678370802379440

33. Doucet $O$, Simard G, Tremblaya M. L'effet médiateur du soutien et de la confiance dans la relation entre le leadership et l'engagement $($ French $)=$ Leadership and Commitment: The 
Mediating Role of Trust and Support. Relations industrielles 2008; 63: 625-47.

34. Christian MS, Garza AS, Slaughter JE. Work engagement: a quantitative review and test of its relations with task and contextual performance. Personnel Psychology 2011; 64: 89136. doi: 10.1111/j.1744-6570.2010.01203.x

35. Barrick MR, Mount MK, Li N. The theory of purposeful work behavior: the role of personality, higher-order goals, and job characteristics. Acad Manage Rev 2013; 38: 132-53. doi: 10.5465/amr.2010.0479

36. Marchand C, Vandenberghe C. Envergure du poste et engagement : le rôle modérateur du soutien et des relations avec le supérieur $($ French)= Job Scope and Affective Commitments: The Moderating Role of Perceived Organizational Support and Leader-Member Exchange. Relations industrielles 2014; 69: 621-44.

37. Kanfer S. Authors on the Road. New Leader 2008; 91: 14-6.

38. Schaufeli WB, Bakker AB, Salanova M. The measurement of work engagement with a short questionnaire: a cross-national study. Educ Psychol Meas 2006; 66: 701-16.

39. Viljevac A, Cooper-Thomas HD, Saks AM. An investigation into the validity of two measures of work engagement. International Journal of Human Resource Management 2012; 23: 3692-709. doi: $10.1080 / 09585192.2011 .639542$

40. Great Managers Boost Employee Engagement. Journal of Financial Planning 2014; 27: 10.

41. Nilsson P, Andersson HI, Ejlertsson G. The Work Experience Measurement Scale (WEMS): A useful tool in workplace health promotion. Work 2013; 45: 379-87. doi: 10.3233/WOR-121541

42. Hultell D, Gustavsson JP. A psychometric evaluation of the Scale of Work Engagement and Burnout (SWEBO). Work 2010; 37: 261-74. doi: 10.3233/WOR-2010-1078

43. Soane E, Truss C, Alfes K, Shantz A, Rees C, Gatenby M. Development and application of a new measure of employee engagement: the ISA Engagement Scale. Human Resource Development International 2012; 15: 529-47. doi: 10.1080/13678868.2012.726542
44. Baron $A$. What do engagement measures really mean? Strategic HR Review 2013; 12: 21-5. doi: 10.1108/14754391311282450

45. Taris TW, Kompier MAJ, De LangeAH, Schaufeli WB, Schreurs PJ. Learning new behaviour patterns: A longitudinal test of Karasek's active learning hypothesis among Dutch teachers. Work Stress 2003; 17: 1-20. doi: 10.1080/0267837031000108149

46. Simon B. Prism: Shortcut to data analysis. 1995. p. 56.

47. Freeney $Y$, Fellenz MR. Work engagement as a key driver of quality of care: a study with midwives. J Health Organ Manag 2013; 27: 330-49.

48. Yüksel H. The Concept of Workaholism As The Extreme Point in Work Engagement, Its Individual and Organizational Outcomes. International Journal of Alanya Faculty of Business 2014; 6: 11930.

49. Shimazu A, Schaufeli WB, Kubota K, Kawakami N. Do workaholism and work engagement predict employee well-being and performance in opposite directions? Ind Health 2012; 50: 316-21.

50. Attridge M. Measuring and managing employee work engagement: a review of the research and business literature. J Workplace Behav Health 2009; 24: 383-98. doi: 10.1080/15555240903188398

51. Halm B. Employee engagement: a prescription for organizational transformation. Adv Health Care Manag 2011; 10: 77-96.

52. Ruck K, Welch $M$. Valuing internal communication; management and employee perspectives. Public Relat Rev 2012; 38: 294302. doi: 10.1016/j.pubrev.2011.12.016

53. Mishra K, Boynton L, Mishra A. Driving Employee Engagement: The Expanded Role of Internal Communications. Journal of Business Communication 2014; 51: 183-202. doi: 10.1177/2329488414525399

54. Fleming J. From gallup: why engagement is essential. Strategic Communication Management 2009; $13: 7$.

55. Lerner M. Turn everyday tasks into employee engagement opportunities. Radiol Manage 2011; 33: 16.

56. Dávila N, Piña-Ramírez W. What Drives Employee Engagement? It's All About the 'l'. Public Manager 2014; 43: 6-9. 